\title{
MODERNIDADE LÍQUIDA E CONSUMISMO NO PENSAMENTO DE ZYGMUNT BAUMAN
}

\author{
LIQUID MODERNITY AND CONSUMERISM IN ZYGMUNT BAUMAN'S THINKING
}

MODERNIDAD LÍQUIDA Y CONSUMISMO EN EL PENSAMIENTO DE ZYGMUNT BAUMAN

\author{
Fábio Antonio Gabriel \\ Doutor em Educação, Universidade Estadual de Ponta Grossa - UEPG \\ Bolsista de doutorado-bolsa CAPES/Fundação Araucária. \\ E-mail: fabioantoniogabriel@gmail.com

\section{Ana Lúcia Pereira} \\ Doutora em Ensino de Ciências e Educação Matemática (UEL). \\ Professora Adjunta no Departamento de Matemática e Estatística e nos Programas de Pós-Graduação em \\ Educação e em Ensino de Ciências e Educação Matemática na UEPG. Bolsista Produtividade da Fundação \\ Araucária. E-mail: anabaccon@uepg.br
}

Ana Cássia Gabriel

Bacharel em Direito, Faculdade Integradas de Ourinhos, graduanda em Ciências Sociais pela UNIMES - FIO. E-mail: anacgabriel.ag@gmail.com

\section{RESUMO}

Este artigo analisa a concepção sobre modernidade líquida, concebida pelo filósofo e sociólogo Zygmunt Bauman. O filósofo aponta esse entendimento como característica da efemeridade aliada a um exacerbado consumismo na sociedade contemporânea. Tais peculiaridades norteiam a compreensão do pensamento desse filósofo. A metodologia deste trabalho vale-se da pesquisa bibliográfica para um estudo descritivo, crítico das contribuições desse sociólogo ao conceito de modernidade líquida. Os resultados alcançados apontam no sentido de que a sociedade hodierna se tornou refém da modernidade, que mergulha na fugacidade, em que tudo flui muito rapidamente, e diante da qual a modernidade sólida não resistiu, deixando-se sucumbir. Infere-se, também, que, ao buscar suprir a sua falta, o homem, influenciado pelo capitalismo, tornou-se extremamente consumista, sem se dar conta, muitas vezes, das consequências que essa atitude pode provocar para si, para o outro e para o mundo.

Palavras-chave: Modernidade líquida; Consumismo; Ética.

\begin{abstract}
This paper analyzes the conception about liquid modernity, conceived by the philosopher and sociologist Zygmunt Bauman. The philosopher points to this understanding as a characteristic of ephemerality coupled with an exacerbated consumerism in contemporary society. Such peculiarities guide the understanding of this philosopher's thinking. The methodology of this text uses the bibliographic research for a descriptive study, critical of the contributions of this sociologist to the concept of liquid modernity. The achieved results point to the fact that today's society has become hostage to modernity, plunged into the fleetingness, in which everything flows very quickly and, in the face of which solid modernity has not resisted, letting itself succumb. It is also inferred that, in seeking to compensate for its lack, man, influenced by capitalism in the current context, has become extremely consumerist, often unaware of the consequences that this attitude can have for himself, to the other and to the world.
\end{abstract}

Keywords: Liquid modernity; Consumerism; Ethics. 


\section{RESUMEN}

Este artículo analiza la concepción sobre modernidad líquida, concebida a partir del filósofo y sociólogo Zygmunt Bauman. El filósofo apunta ese entendimiento como característica de la fugacidad, aliada a un exacerbado consumismo en la sociedad contemporánea. Tales peculiaridades orientan la comprensión del pensamiento de este filósofo. La metodología de este estudio se vale de investigación bibliográfica para un estudio descriptivo, crítico de las contribuciones de este sociólogo al concepto de modernidad líquida. Los resultados alcanzados apuntan en el sentido de que la sociedad actual se ha convertido en rehén de la modernidad, que se hunde en la fugacidad, en que todo fluye muy rápidamente, y ante la cual la modernidad sólida no resistió, dejándose sucumbir. Se infiere también que, al buscar suplir su falta, el hombre, influenciado por el capitalismo, se ha vuelto extremadamente consumista, sin darse cuenta, muchas veces, de las consecuencias que esa actitud puede provocar para sí mismo, para el otro y para el mundo.

Palabras-clave: Modernidad líquida; Consumismo; Ética.

\section{INTRODUÇÃO'}

Zygmunt Bauman destaca-se como sociólogo contemporâneo e sua produção bibliográfica enriquece o entendimento do cotidiano atual, ao abordar temas como o consumismo. Para Bauman (2001), vivemos em tempos de modernidade líquida; em outras palavras, tudo perde a solidez que o caracteriza. Assim sendo, se a solidez da pedra caracteriza a perenidade, o que é líquido se esvai rapidamente em segundos, como a água que não podemos represar nas mãos, pois é impossível conter um líquido senão em frascos. Isso implica uma existência que não vivencia a realidade da vida de forma duradoura, mas de forma fluida, fugaz, como se percebe nos hábitos, no comportamento e nos próprios relacionamentos humanos que não duram muito tempo.

Outra temática que abordaremos neste artigo evidencia o consumismo tão arraigado na sociedade contemporânea. Percebemos como as pessoas criam sua própria identidade na medida em que conseguem consumir mais; o consumismo, assim, é um imperativo que move o homem na atualidade. Shopping centers destacam-se como os novos templos, templos do consumo da sociedade contemporânea. O dia de domingo, para os cristãos, dia do Senhor, para uma significativa parcela da população, tornou-se o dia do consumo. O vazio existencial produzido pela modernidade líquida torna-se a mola propulsora do imperativo categórico do consumir cada vez com mais sofreguidão.

Como opção de organização do processo de escrita, organizamos o artigo da se-

$1 \quad$ O presente trabalho foi realizado com apoio da Coordenação de Aperfeiçoamento de Pessoal de Nível Superior - Brasil (CAPES) - Código de Financiamento o01 e da Fundação Araucária. 
guinte forma: na próxima seção, falamos sobre a modernidade líquida, conforme apresentada por Bauman (2001). Na seção seguinte, tratamos do consumismo como expressão sintomática da sociedade capitalista, em que o consumir se tornou a mola propulsora da própria identidade das pessoas. E, por fim, apresentamos as considerações finais relacionando os conceitos do sociólogo estudados com a apropriação no âmbito da educação.

\section{Modernidade líquida em Bauman}

Bauman (2001) constata a obliteração da modernidade sólida, que sucumbe ao tempo, esvai-se como a água entre os dedos por sua liquidez. Para o sociólogo, não podemos subestimar a “[...] profunda mudança que o advento da 'modernidade fluida' produziu na condição humana" (BAUMAN, 2001, p. 15). A modernidade líquida produziu um novo ciclo nas condições humanas. O esforço do iluminismo foi justamente tratar de realizar o ideal da modernidade, de emancipar o ser humano. Tornar o ser humano um iluminado pela razão e movido pelas luzes do entendimento era o seu imperativo. No entanto, para Bauman (2001), ocorre, na atualidade, um movimento de valorização da subjetividade e de implosão dos valores postulados pela razão. Em vez de falar em uma pós-modernidade, Bauman (2001) sugere uma modernidade líquida em oposição à modernidade sólida que, paulatinamente, derreteu. Ser moderno, para Bauman (2001), significa “[...] ser incapaz de parar e ainda menos capaz de ficar parado. O homem moderno persegue o novo, mas, após a conquista de tal bem, dele rapidamente se enfastia; insaciável, persegue novos anseios norteado sempre pelo eterno 'adiamento da satisfação”' (BAUMAN, 2001, p. 37).

Vivemos a modernidade líquida, segundo o pensamento de Bauman, que reflete a instauração de um processo de liquidez, diante do qual a solidez sucumbe. Silva, Mendes e Alves (2015) afirmam que, na modernidade líquida, há um trânsito da posição do ser humano de agente passivo para agente ativo. Isso porque, na modernidade sólida, tudo sucedia como determinismo preestabelecido por uma ordem teleológica. Romper com a sociedade sólida produz, então, um movimento de relegar a perenidade dos entendimentos que se mantinham, das metanarrativas que guiavam a humanidade e abriam a possibilidade de novas narrativas. 
Rojas (2016) entende o homem moderno como que vivendo na era do plástico, “[...] dele deriva certo pragmatismo do descartável” (ROJAS, 2016, p. 20). Na visão do autor, vive-se na modernidade uma cultura niilista e uma crise de valores transcendentais. Para Rojas (2016, p. 73), “[...] reina o consumismo no lugar da sobriedade, o estresse no lugar da vida organizada e harmoniosa”. A modernidade conduz a uma vida light, a uma existência vazia. O entendimento do autor de uma vida light é uma vida sem solidez, líquida, transitória, sem profundidade, sem raízes.

Souza (2012) apresenta sua intepretação a respeito daquilo que significa o derretimento dos sólidos na perspectiva de Bauman, afirmando que se a Idade Média apregoou a valorização da família, a Igreja e a comunidade, o “derretimento dos sólidos” propôs eliminar todos esses "empecilhos" e o líquido seria a nova ordem que impera (SOUZA, 2012). Partindo da interpretação de Souza (2012), inferimos que o anseio pela modernidade líquida pretende superar todo o evento da Idade Média, em que se exercitava a manipulação do poder ideológico, prevalecendo uma única visão de mundo. A Idade Média deixou sua contribuição para o pensamento e para a história, mas prevalecia o anseio por um espírito dogmático. A filosofia cartesiana talvez tenha sido o primeiro movimento a destacar-se em direção ao rompimento com os dogmatismos da tradição filosófica, ao propor o movimento da dúvida metódica. Duvidar de tudo, eis a máxima cartesiana e, por meio da dúvida, chegar a um conhecimento indubitável, certo, seguro. A modernidade líquida maximiza o pensamento cartesiano e estabelece a insegurança da fluidez como o alicerce para uma vida líquida.

Souza (2012) ajuda-nos a compreender as características da sociedade moderna líquida:

A sociedade moderna líquida é chamada por Bauman de "indústria de eliminação de resíduos. Quanto mais rápido os produtos colocados à disposição de clientes ávidos caem em desuso, melhor é para os responsáveis por alimentar essa fábrica de desejos. As mercadorias tornadas desperdícios são removidas e substituídas, sua eliminação exige depósitos adequados (um dos grandes problemas contemporâneos está justamente em que destino dar a esses resíduos). A sociedade contemporânea rubrica, dessa forma, seu status de produtora incomensurável de detritos não totalmente danificados. (SOUZA, 2012, p. 40). 
Nessa perspectiva, o conceito de modernidade líquida relaciona-se a outro conceito que investigamos, o do consumismo que, segundo nossa leitura, impõe-se como um dos sintomas da sociedade líquida. Trata-se de uma sociedade que busca consumir cada vez mais. Com o avanço crescente da tecnologia, também se percebe que os produtos se desatualizam, perdem a "validade" diante do novo que continuamente surge com uma nova tecnologia e às pessoas Ihes resta substituir o objeto tão ansiado por outro, mais atualizado. As pessoas tornam-se escravas do consumismo, e, doloroso, não só do consumo, mas também do trabalho. Impõe-se trabalhar mais, para ganhar mais dinheiro, para poder comprar e pagar pelos produtos que consideram necessários para a vida.

No mundo líquido, tudo é um constante vir a ser, como nos dizia Heráclito, na sua filosofia. O mundo líquido é um mundo de instabilidades, conforme nos apresenta Bauman (2011):

Para resumir a história: esse mundo líquido moderno, sempre nos surpreende; o que hoje parece correto e apropriado amanhã pode muito bem se tornar fútil, fantasioso ou lamentavelmente equivocado. Suspeitamos que isso possa acontecer e pensamos que, tal como o mundo que é nosso lar, nós, seus moradores, planejadores, atores, usuários e vítimas, devemos estar sempre prontos a mudar: todos precisam ser, como diz a palavra da moda, flexíveis. (BAUMAN, 2011, p. 8).

Nessa perspectiva, “[...] as relações virtuais derrotam facilmente a vida real” (BAUMAN, 2011, p. 23). O mundo virtual possibilita uma fuga ao menos momentânea dos conflitos do mundo real. Com um clique, amizades são desfeitas. Tudo é muito prático, porém as relações se tornam efêmeras, fugazes. No mundo virtual, identidades também podem ser forjadas e se vive nas redes sociais uma dupla ou multipersonalidade.

Nesse contexto, “[...] o contato face a face é substituído pelo contato tela a tela dos monitores" (BAUMAN, 2011, p. 27). Assim se constitui o mundo líquido, como fonte de centenas de novos contatos, todos superficiais. No dia de aniversário, muitos recebem mais "parabéns" de forma online do que presencialmente; outrossim, os "parabéns" online muitas vezes caminham para limitar-se à troca de mensagens apenas no dia do aniversário. Vive-se, nesse contexto, as consequências da modernidade líquida em que os relacionamentos se tornam superficiais, artificiais.

Assim, a vida se torna um "[...] colapso do pensamento, do planejamento e da 
ação no longo prazo" (BAUMAN, 2007, p. 9). Vertiginosa se constata a velocidade das informações, que também são efêmeras, passageiras. O mundo transita por uma crise ecológica jamais vista no seio da modernidade, não se avaliam as consequências das ações para as futuras gerações e a inconsequência pode determinar a inviabilidade da preservação da vida humana no planeta. Por um lado, parece que o ser humano nunca foi tão livre; por outro, esse mesmo ser se vê condicionado pelo capitalismo continuamente.

\section{O consumismo segundo bauman}

Bauman (2011) apresenta, como sintoma da modernidade líquida presente na sociedade contemporânea, o consumismo, que não consiste no hábito de se consumir apenas aquilo de que se necessita, mas representa o excesso de aquisições desnecessárias, supérfluas. As pessoas consomem, muitas vezes, para ostentação. Desse modo, as compras não têm relação com necessidades, mas são realizadas "[...] pelo tipo de imagem que gostaríamos de vestir e por modos de fazer com que os outros acreditem que somos" (BAUMAN, 2001, p. 87). Trata-se de um desejo caprichoso de consumir cada vez mais. Nesse sentido, Bauman (2001) destaca que o consumismo é a manifestação da quebra dos sólidos em sua máxima potência, produzindo um mundo dos líquidos em que tudo é rapidamente desfeito e assume novas configurações.

A vida, em tal perspectiva, é movida pelo consumo, pela sedução capitalista, pela ilusão do ter, do poder para inflar a própria autoestima e identidade pessoal. Predomina o vício das compras como "[...] manifestação aberta de instintos materialistas e hedonistas adormecidos" (BAUMAN, 2001, p. 95). Nesse contexto, valorizamos o hedonismo momentâneo; buscamos um prazer imediato em contraposição a uma vida plena como metafísica. O próprio ideal de uma vida eterna sucumbe diante do imperativo de se viver uma vida momentânea, ilusória, supostamente feliz. Permeia essa visão consumista uma visão materialista da vida, já que não se busca a vida eterna, mas, sim, uma vida maximamente feliz pela posse dos bens terrestres, sendo o consumo essencial nesse processo.

Fragoso (2011) apresenta sua interpretação do pensamento de Bauman que apresenta uma sociedade se torna cada vez mais consumista e, em consequência, infeliz; onde 
a busca pela felicidade é uma ilusão na sociedade consumista, porque, na interpretação do pesquisador, os bens materiais não logram atingir uma vida completamente feliz justamente porque as aspirações se alimentam de desejos fugazes. "A arte da vida na versão líquida da modernidade desincumbe o indivíduo de se identificar" (FRAGOSO, 2011, p. 115). Nessa perspectiva, entendemos a importância do pensamento de Bauman que formula conceitos relevantes para se pensar a própria existência.

Fontenelle (2017) defende que a cultura do consumo é a cultura do capitalismo em que se buscam cada vez mais formas de consumir para vender mais e, assim, alavancar o mercado do vender e do comprar. A autora defende que a cultura do consumo surge principalmente no final do século XI, ganhando formatação ao longo do século XX. A autora entende a importância da Revolução Industrial e da Revolução Francesa no processo da consolidação do capitalismo moderno. Nas palavras da autora:

Isso nos leva a concluir que a história da cultura do consumo pode ser compreendida a partir do momento em que as grandes corporações capitalistas somaram forças com o governo a fim de inaugurarem uma era de fusão entre propaganda e advertising, no sentido de aderência a um sistema ideológico que propunha estilo de vida fundamentalmente moldado pelo consumo. E que esse projeto entre os negócios e a política contou com o apoio imprescindível da psicologia existente na época. (FONTENELLE, 2017, p. 53).

O existencialismo é uma corrente de filosofia contemporânea cujo enfoque principal é uma reflexão sobre a condenação à liberdade que todos seres humanos estão determinados. Não é possível deixar de ser livre. Dialogando com Fragoso (2011), percebemos uma ilusão no processo de liberdade da modernidade líquida. Na verdade, estamos cada vez mais presos ao próprio capitalismo, que incute em nossa mente a ideia de que somos livres. Na verdade, somos livres na medida em que o capitalismo nos permite ser e não ultrapassamos esse limite; o capitalismo nos oferece uma ilusão de que somos livres. Colombo (2012, p. 26) entende que, no contexto de uma sociedade consumista, “[... a liberdade está intimamente ligada à perfeição, que também está ligada a uma qualidade coletiva da massa e a multiplicidade de objetos e desejos" (COLOMBO, 2012, p. 26).

De cidadãos livres a cidadãos consumidores: eis a marca que a sociedade líquida impõe aos seus habitantes. Urge pensar na relevância do consumir no processo em que 
tudo está em constante mudança. Poderíamos dizer que se consomem também ideias, e estas são produzidas e consumidas rapidamente sem se constituir em doutrinas. Aliás, não há mais espaço para doutrinas, dogmas, tudo agora é totalmente fluido, fugaz e efêmero.

Bauman (2008) destaca o quanto a sociedade de consumo atribui poder às pessoas para que se sintam bem enquanto compram, contribuindo, por outro lado, para o entendimento de que as pessoas, nesse processo, são, segundo o mercado, encaradas como mercadoria. A vida nas redes sociais também cria um ambiente artificial em que o ilusório parece real. Principalmente para os adolescentes, que vivem imersos em "confessionários eletrônicos portáteis" (BAUMAN, 2008, p. 9). Trata-se de uma nova sociedade que não tem limites para a separação entre privado e público. É preciso ressaltar que nem sempre as pessoas expõem o privado que as identificaria realmente, mas, muitas vezes, expõem imagens ideais, em nada correspondentes à realidade, e, assim, são compartilhadas com o público.

Bauman (2008) expõe a ilusão das pessoas no ato frenético de consumir, e tais pessoas sequer percebem que se tornam também mercadorias. Nas palavras de Bauman (2008, p. 20), “[...] a característica mais proeminente da sociedade de consumidores - ainda que cuidadosamente disfarçada e encoberta - é a transformação dos consumidores em mercadoria". Na sociedade dos consumidores, as pessoas aparentam estar alegres quando compram e aparentam uma ilusão identitária de que comprar mais poderá contribuir para tornar esse mesmo comprador alguém de valor. Bauman (2008) trabalha a ideia de que o consumismo, com todos os seus fetiches, acaba se tornando a "[...] principal força propulsora e operativa da sociedade" (BAUMAN, 2008, p. 41).

Bauman (2008) estabelece uma distinção clara entre consumo e consumismo: o consumo em si não é negativo, é uma necessidade vital humana; já o consumismo é característica de uma sociedade cujos valores são demasiadamente materialistas e o consumir está associado à concepção de identidade dos sujeitos de uma determinada sociedade.

A modernidade líquida relaciona-se ao consumismo (BAUMAN, 2008), na medida em que tudo é líquido; as pessoas tendem ao consumismo instantâneo como forma de superar um vazio existencial. Por um lado, a sociedade de consumo promete realizar os 
desejos das pessoas como nenhuma outra sociedade realizou; por outro lado, é uma sociedade de insatisfeitos porque, quando um desejo é satisfeito, surge instantaneamente outro desejo e assim sucede infinitamente, pois o sujeito é movido pelo desejo. Ainda sobre o consumismo, Bauman (2008) afirma:

Além de ser um excesso e um desperdício econômico, o consumismo também é, por essa razão, uma economia do engano. Ele aposta na irracionalidade dos consumidores e não em suas estimativas sóbrias e bem informadas; estimula emoções consumistas e não cultiva a razão. Tal como ocorre com o excesso e o desperdício, o engano não é um sinal de problema na economia de consumo. Pelo contrário, é sintoma de sua boa saúde e de que está firme sobre os trilhos, é a marca distintiva do único regime sob o qual a sociedade de consumidores é capaz de assegurar sua sobrevivência. (BAUMAN, 2008, p. 65).

Desde Aristóteles o ser humano é entendido como animal racional. Bauman (2008) aponta justamente para o aspecto irracional do ser humano, que impensadamente se deixa levar pelo consumismo. O mercado consumista trabalha com a ideia de que antigas ofertas não agregam mais valor, o objeto de que se dispõe já está desatualizado, por essa razão é preciso comprar outro. Este outro, logo mais também estará desatualizado e assim sucessivamente. Nas palavras de Bauman (2008, p. 142): " Relembremos que os consumidores são levados pela necessidade de se ‘comodificarem', de se transformarem em mercadorias atraentes - e pressionados a exibir os estratagemas e expedientes usuais da prática de marketing para esse propósito".

Pensando no campo educacional, constata-se, na contemporaneidade, o quanto o próprio fenômeno educativo é concebido como uma mercadoria, e o aluno é cliente. Trata-se de banalizar o ato educativo e considerá-lo apenas uma mercadoria. Assim, a visão de que aluno é cliente é difundida não apenas no âmbito da educação privada, mas também da educação pública. "Temos que tratar nosso aluno como cliente”, diz o slogan capitalista. Com essa crítica, não queremos dizer que não se deva tratar bem o aluno, mas que a relação entre professor e aluno não se estabelece em tais termos, pois, como destacam Baccon e Arruda (2015, p. 465), “[...] é notória a importância das relações criadas nesse

$\overline{2}$ Bauman (2011, p. 83, grifos do autor) esclarece sobre o consumismo nos seguintes termos: "O consumismo é um produto social, e não o veredicto inegociável da evolução biológica. Não basta consumir para continuar vivo se você quer viver e agir de acordo com as regras do consumismo. Ele é mais, muito mais que o mero consumo. Serve a muitos propósitos; é um fenômeno polivalente e multifuncional, uma espécie de chave mestra que abre todas as fechaduras, um dispositivo verdadeiramente universal". 
processo e é por isso que a profissão de professor passa fundamentalmente por saber estabelecer relações". O ambiente escolar é responsável por formar cidadãos conscientes, eficientes, críticos e responsáveis dentro da sociedade, e reduzir a educação a uma mercadoria é de uma pobreza deplorável, nada edificante.

Também impactada pela modernidade líquida “[... ] a cultura está vivendo uma espécie de seção da loja de departamentos" (BAUMAN, 2011, p. 91). A Escola de Frankfurt já havia anunciado o conceito de indústria cultural como o fenômeno em que a cultura é transformada em mercadoria. No contexto de modernidade líquida, um juramento de fidelidade, um compromisso em longo prazo é visto de maneira negativa porque, nesse ângulo, tudo é fugaz.

No mundo do consumo, desempregados diante da sociedade de produtores encontram-se à margem, são desprezíveis porque não podem consumir; assim, “[...] a promessa de ser um consumidor diligente e a reivindicação do status de consumidor não serão suficientes para uma pessoa ser admitida na companhia dos consumidores" (BAUMAN, 2005, p. 23). Ao observarmos o cenário internacional, podemos constatar que o capitalismo globalizado produz refugiados que são o "refugo da globalização" (BAUMAN, 2005, p. 77). A mesma sociedade que produz cada vez mais lixo é a sociedade em que muitos não querem ocupar a função de lixeiros. Nas palavras de Bauman (2005, p. 77): “A cada triunfo sucessivo do consumismo, cresce a necessidade de coletores de lixo, enquanto se reduz a oferta de pessoas dispostas a engrossar suas fileiras" (BAUMAN, 2005, p. 77).

\section{CONSIDERAÇÕES FINAIS}

No presente artigo, tivemos como objetivo analisar a concepção do filósofo Zygmunt Bauman sobre modernidade líquida e alguns de seus efeitos na sociedade contemporânea. Bauman (2001) não trabalha com o conceito de pós-modernidade, mas sim, com o conceito de modernidade líquida, que se caracteriza pela fluidez e pela efemeridade. Nada se solidifica nesse processo; pelo contrário, tudo se esvai. O que antes era sólido, desfaz-se 
facilmente, e, assim, está decretado o fim das metanarrativas e dos ideais iluministas de emancipação humana.

Um dos sintomas desta sociedade que se caracteriza como modernidade líquida é o hábito consumista, diante do qual se abandonam os ideais transcendentes; apela-se para o consumo acentuado de bens materiais. Não se trata de possuir bens por uma questão de necessidade, mas de ostentar uma identidade virtual possibilitada pela posse de bens, ilusória, fugaz.

Toda essa questão acaba gerando um consumismo exacerbado, em que as pessoas não percebem o que existe de fato por trás dessa atitude, além das suas consequências para as relações com o mundo, com o outro e consigo mesmas. Outra questão apontada é que, cada vez mais, estamos presos ao próprio capitalismo, que incute em nossa mente a ideia de que somos livres. Entretanto, mesmo inconsciente, o sujeito pensa que, ao atender o seu desejo de consumismo, para suprir a sua falta, torna-se livre e exerce a sua liberdade. Esta, na verdade, o amarra ainda a essa falta, que nunca poderá ser suprida, pois, na modernidade líquida, o consumismo instantâneo busca superar um vazio existencial (BAUMAN, 2008), que jamais poderá ser preenchido, porque o homem já nasce faltoso e desejoso.

A modernidade líquida e o consumismo, representam, portanto, muito mais do que o excesso de aquisições desnecessárias, supérfluas. Representam um sujeito que, embora viva em pleno século XXI, rodeado de mudanças e evoluções em todos os âmbitos, continua preso em sua “caverna”. Nesse caso, a alegoria da caverna de Platão já não leva a pensar nos sujeitos trancados em suas casas como se fossem cavernas, pois até isso foi alterado por conta da modernidade líquida. Hoje os homens vivem enclausurados em suas microcavernas, ou seja, nos seus computadores, nos seus celulares, no meio em que sentem que a sua falta está sendo preenchida. Todo esse contexto faz com que as pessoas não vivenciem mais a realidade da vida, que não aproveitem o momento presente, o aqui e o agora, e, com isso, não percebem também que a sua vida está se esvaindo por ser fluida e fugaz.

O estudo crítico sobre a obra de Bauman (2008) aponta que a sociedade hodierna 
se tornou refém da fugacidade; nela tudo flui muito rapidamente; diante dela a modernidade sólida não resistiu, deixou-se sucumbir. Infere-se também que, ao buscar suprir a falta de sentido para a vida, o homem tornou-se extremamente consumista, sem se dar contadas consequências que essa atitude pode provocar para si, para o outro e para o mundo.

As pessoas, na maioria das vezes, acabam não percebendo que o tempo está passando, e que este é implacável e que não volta mais. Parece urgente, portanto, que se deem conta disso, que olhem à sua volta e que percebam como as suas relações estão sendo construídas. É importante que as pessoas adquiram consciência da sua própria existência e do outro. Nesse sentido, utilizando o conceito do cogito cartesiano, parece urgente que as pessoas percebam que o seu desejo, que a sua falta, não podem estar presos ao "Consumo, logo existo!", pois isso remete à ideia de ter; ao consumir "eu existo" para outro, que "me vê" diferente, ou que pelo menos "me vê". Nesse contexto, a máxima do cogito cartesiano, poderia ser: “Vivo, logo existo!”, incluindo a ideia de um viver que seja para si e não para o outro; um viver que encontre sentido e significado em tudo o que se faz, na certeza de que se está construindo não só um lugar no mundo, mas um lugar onde todos possam ocupar seu espaço, um lugar onde as pessoas sejam pelo menos "vistas", “percebidas” e onde, quiçá, se sintam pertencentes a esse "lugar”.

\section{REFERÊNCIAS}

BACCON, A.; ARRUDA, S. M. Estilos de gestão da sala de aula: uma análise a partir da ação docente. Práxis Educativa, Ponta Grossa, v. 10, n. 2, p. 463-487, jul./dez. 2015.

BAUMAN, Z. 44 cartas do mundo líquido moderno. Tradução Vera Pereira. Rio de Janeiro: Zahar, 2011.

BAUMAN, Z. Modernidade líquida. Tradução Plínio Dentzien. Rio de Janeiro: Zahar, 2001.

BAUMAN, Z. Tempos líquidos. Tradução Carlos Alberto Medeiros. Rio de Janeiro: Zahar, 2007.

BAUMAN, Z. Vida para consumo: a transformação das pessoas em mercadoria. Tradução Carlos Albertos Medeiros. Rio de Janeiro: Zahar, 2008.

BAUMAN, Z. Vidas desperdiçadas. Tradução de Carlos Alberto Medeiro. Rio de Janeiro: Zahar, 2005. 
COLOMBO, M. Modernidade: a construção do sujeito contemporânea e a sociedade de consumo. Revista Brasileira de Psicodrama, São Paulo, v. 20, n. 1 p. 25- 39, jun. 2012.

FONTENELLE, I. F. Cultura do consumo: fundamentos e formas contemporâneas. Rio de Janeiro: FGV, 2017.

FRAGOSO, T. de O. Modernidade líquida e liberdade consumidora: o pensamento crítico de Zygmunt Bauman. Revista Perspectivas Sociais, Pelotas, ano 1, n. 1, p. 109-124, mar. 2011

ROJAS, E. O homem moderno: a luta contra o vazio. Curitiba: Editora do Chain, 2016.

SILVA, R. B.; MENDES, J. P. S.; ALVES, R. dos S. L. O conceito de líquido em Zygmunt Bauman: contemporaneidade e produção de subjetividade. Athenea Digital, Bellaterra, Espanha, v. 15, n. 2, p. 249-264, jul. 2015.

SOUZA, W. M. L. Uma excursão pelo contemporâneo a partir do conceito de modernidade líquida de Zygmunt Bauman. 2012. 112 f. Dissertação (Mestrado em Epistemes Contemporâneas) - Universidade Federal de Mato Grosso, Cuiabá, 2012.

Recebido em: 30/01/2019

Parecer em: 18/09/2019

Aprovado em: 25/10/2019 